UDK 781:784.66

Alenka Barber-Keršovan

Institut für Musikwinenschaft, Universität, Hamburg

Inštitut za muzikologijo Univerze v Hamburgu

\title{
Musicology Went Pop: Raziskovanje globalnih glasbenih tokov skozi prizmo nacionalnih šol in drugih znanstvenih konvencij
}

\section{Musicology Went Pop: The research of Global Musical Trends through the Prism of National Schools and Other Scholarly Conventions}

Ključne besede: kulturološke študije, študije spolov, glasbena pedagogika, glasbene subkulture, interdisciplinarnost

POVZETEK

Prav tako kot v ZDA in Veliki Britaniji je bil tudi v Zvezni republiki Nemčiji eden od prvih pristopov $\mathrm{k}$ raziskovanju popularne glasbe sociološki. Nadaljnji impulzi so prihajali s področja glasbene pedagogike, V okviru nemške znanstvene organizacije $z$ imenom Arbeitskreis Studium Populärer Musik e.V. se je akademski diskurz o popularni glasbi sprva naslonil na sistematično muzikologijo, nato pa je pričel upoštevati tudi izsledke sorodnih disciplin, med njimi sociologije, etnologije, antropologije, "cultural studies" in "gender studies". S tem se je odprl nov zorni kot približevanja glasbenim fenomenom, ki skuša ujeti $\mathrm{v}$ smiselne aksiome predvsem kompleksnost in polivalentnost glasbenih procesov. $\mathrm{Na}$ osnovi teh izkušenj prestavlja za avtorico osnovni predmet muzikološkega raziskovanja glasbeno življenje kot živ in nenehno se spreminjajoč organizem. Zavzema se za celostni pristop $\mathrm{k}$ raziskovalni materiji, metodološki pluralizem, interdisciplinarnost raziskovanja, iskanje dialoga $\mathrm{z}$ drugimi znan-
Keywords: cultural studies, gender studies, music education, music subcultures, interdisciplinarity

SUMMARY

As in the US and in Great Britain, also in the Federal Republic of Germany the first studies in popular music were sociological. Further impulses came from music education. In the framework of the German scientific organisation called Arbeitskreis Studium Populärer Musik e.V. the academic discourse on popular music was originally rooted in the systematic musicology. Later on, it opened up towards a number of related disciplines, such as sociology, ethnology, anthropology, cultural and gender studies. Herewith a new approach towards the musical phenomena unfolded, focusing on the complexity and polyvalence of musical processes. Based on these experiences, and as regards the author, the key subject of the musicological research represents the musical life in terms of a persistently changing living organism. She supports a holistic approach towards the topic of research, interdisciplinary and methodological pluralism, the search for dialogue with related scientific discipli- 


\section{MUZIKOLOŠKI ZBORNIK • MUSICOLOGICAL ANNUAL XXXIX}

stvenimi panogami ter vodenje konstruktivnega diskurza med različnimi pogledi, "Šolami" in teoretskimi pozicijami. nes and a constructive exchange between different points of view, "schools", and theoretical positions.

Akademski diskurz na področju raziskovanja popularne glasbe se je prvotno nanašal na teme, ki niso bile primarno glasbeno orientirane. Med pionirje tovrstne raziskovalne dejavnosti sodi David Riesman, ki ga poznamo predvsem po njegovem klasičnem delu "The Lonely Crowd" iz leta 1950 in ki je s svojo študijo o glasbenem vedenju mladih uveljavil nov pristop k obdelavi te tematike. Le-ta je bila dotlej predvsem lingvistično usmerjena in se je izčrpala $\mathrm{v}$ analizi besedil na osnovi literarne teorije.

V 60. letih prejšnjega stoletja se je pojavilo raziskovanje glasbenih subkultur. Izhajalo je iz Centre for Contemporary Cultural Studies Univerze v Birgminghamu in je neločljivo povezano z imeni Stan Cohen, John Clarke, Theodor Roszak, Dick Hebdige und Mike Brake. Subkulturna teorija je pomembno odjeknila tudi v Sloveniji, saj je v davnih 80. letih, ko so punk, alternativna kultura, Laibach in Neue Slowenische Kunst dodobra razburkali slovensko javnost, služila t.i. alternativni inteligenci kot interpretacijski model razlage dogodkov v smislu mita o rock'n'roll revoluciji. V centru subkulturnih teorij, ki so slonele na raziskovanju deviantnega vedenja in kriminologije, so se namreč nahajale naslednje tri teze:

1. Glasba in drugi izrazni mediji, kot so npr. plakat, film ali video, tvorijo delne aspekte subkulturnega stila. Pod tem izrazom razumemo celoto vseh tistih konstitutivnih elementov, ki so bistveni za konstrukcijo kulturne identitete neke določene skupine. Subkulturni stil deluje tako integrativno kakor tudi dezintegrativno, saj krepi pripadnost k neki določeni skupini in jo hkrati razmejuje od drugih oziroma drugačnih kulturnih grupacij.

2. Med vsemi konstitutivnimi elementi nekega subkulturnega stila (glasba, tekst, ikonografija, image, vedenjski rituali, uporaba jezika v smislu žargona ali argota) obstaja simbolična enakoznačnost, ki jo je raziskovanje glasbenih subkultur poimenovalo homologija. Subkulturni stil je zategadelj več kot le skupek svojih konstitutivnih elementev in se prezentira kot celostna, zaokrožena oblika glasbenega vedenja.

3. Oblikovanje subkulturnega stila vsebuje druzbeno kritične komponente, saj predstavljajo subkulturni rituali neverbalno obliko upora proti obstoječim družbenim razmeram oziroma razreševanje socialne problematike na simbolični ravni.

Tem tezam primerno sta Stuart Hall in Tony Jefferson njun leta 1975 izdani zbornik ključnih beril s tega področja poimenovala "Resistance Through Rituals. Youth Subcultures in Post-War Britain“. To delo je - poleg sedaj že kultne razprave Dicka Hebdiga "Subkulture - The Meaning of Style" iz leta 1979, upoštevajoče tako različne vzornike kot so Lévi-Strauss, Louis Althusser, Roland Barthes in Julia Kristeva - postavilo tiste temelje, na katerih je slonelo tudi začetno delo leta 1981 ustanovljene mednarodne organizacije $\mathrm{z}$ imenom International Association for the Study of Popular Music. V začetku je bil to majhen krog ljudi - bilo nas je okrog 60 - ki se je pa vztrajno širil, tako da šteje danes ta asocijacija okrog 600 do 800 raziskovalcev na vseh kontinentih. 
International Association for the Study of Popular Music prvotno ni le povezovala istomislečih posameznikov, ampak je dajala tudi vsebinske impulze. Naj navedem vsaj najpomembnejše. To je bilo predvsem vprašanje odnosa med popularno glasbo in politiko, ki je se sloneló na mitu o rock'n'roll revoluciji poznih 60 . let in je bilo levičarsko politično obarvano. Iz istega pomenskega polja so črpale tudi prve razprave o glasbenem marketingu in masovni potrošnji. Glavne spodbude so prihajale iz Velike Britanije. Ena najvidnejših osebnosti tistega časa je bil Simon Frith, po izobrazbi sociolog, hkrati pa tudi glasbeni kritik. Njegova dela so bila prevedena v vrsto tujih jezikov, med drugim tudi v slovenščino oziroma v srbohrvaščino.

Za muzikologe pa je popularna glasba še nadalje predstavljala nepremostljiv problem. Kot je zapisala Susan McClary v članku "Start making sense! Musicology wrestles with Rock", pri tem ni šlo le za tradicionalno nezaupanje klasične muzikologije proti vsemu, kar naj ne bi imelo neke določene estetske vrednosti oziroma kar naj bi se nahajalo na drugi strani demarkacijske meje med t.i. "resnim" in "popularnim", ampak tudi za ključni problem muzikologije, kako govoriti o nečem, kar se pravzaprav izmuzne ubesedenju in lahko hkrati pomeni vse - ali pa tudi nič. Nadaljnji problem je predstavljala metodologija, saj imamo $v$ glavnem opraviti $z$ glasbo, ki ne pozna notnega zapisa oziroma katere srž je - tako kot npr. pri jazzu - le bežno skicirana v t.i. lead-sheetu. Semiotični pristop, kot ga je 1979 v svoji dizertaciji utemeljil Philip Tagg, zatorej v svojem času ni naletel na veliko razumevanja. Konkretno je šlo pri tem za mnogoplastno analizo 50. sekund uvodnega jingla popularne televizijske serije "Kojak", ki je upoštevala poleg glasbe tudi vizualno plast in danes vedno pogosteje služi kot analitični model za raziskovanje filmske glasbe, video-klipov ter reklamnih spotov.

$\mathrm{V}$ poznih 80 . in zgodnjih 90 . letih so se dotlej veljavne, v glavnem sociološko obarvane paradigme razpršile in dale prostor vrsti novih pristopov. Najpomembnejši med njimi so bile t.i. "cultural studies", kot so jih utemeljili v ZDA in ki so se naslanjale na študij komunikacije, semiotike, psihoanalize ter literarne teorije. Pomembne vzpodbude so nadalje prihajale s področja t.i. "gender studies" - pri tem bi rada omenila vsaj Angelo McRobbie - ter postmoderni teoremi v nasledstvu piscev kot so JeanFrançois Lyotard, Gilles Deleuze, Jacques Derrida in Michel Foucault. Hkrati pa je postalo raziskovanje popularne glasbe oziroma popularne kulture tudi predmet drugih znanstvenih panog, predvsem etnologije in antropologije, tako da se po neki analizi predmetnikov ameriških univerz ukvarja s popularno glasbo nič manj kot 60 univerzitetnih disciplin. Nastalo je tudi več raziskovalnih institutov, ki pristopajo $\mathrm{k}$ raziskovanju popularne glasbe iz popolnoma različnih teoretskih pozicij.

V Zvezni republiki Nemčiji oziroma v nekdanji Zahodni Nemčiji je potekala stvar nekoliko drugače. Tudi tukaj je bil eden od prvih pristopov sociološki, pri čemer bi rada omenila predvsem knjigo "Beat, die sprachlose Opposition", ki jo je 1972 izdal Dieter Baacke in ki se je $\mathrm{v}$ glavnem nanašala na subkulturni teorem o popularni glasbi v smislu neme opozicije. Pomembne spodbude pa so prišle tudi iz glasbene pedagogike, saj so se učitelji glasbe znašli pred problemom, da so se v glasbenem pouku osredotočili na klasično glasbo, medtem ko so se njihovi učenci nahajali na drugem glasbenem planetu. Tukaj sta pričela orati ledino predvsem Hermann Rauhe 
in Winfried Pape, ki sta se že v poznih 60. letih pricela zavzemati za to, da mora glasbena vzgoja upoštevati tudi popularno glasbo.

Nadaljnji pomemben mejnik je bila mednarodna konferenca "Neue musikalische Verhaltensweisen der jungen Generation in der industriellen Gesellschaft", ki jo je 1971 izvedel dunajski Mediacult. Brez nepotrebne samohvale bi rada ob tem omenila zanimivo podrobnost, da sem v pedagoškem projektu, ki je sledil tej konferenci, naredila za Mediacult primerjalno analizo avstrijskih in slovenskih učnih načrtov glasbene vzgoje ter o rezultatih poročala na kongresu "International Society for Music Education" v Montreuxu. Obe deželi sta se odrezali enako porazno, saj v takratnih učnih načrtih ni bilo niti besedice o tem, da mora glasbena vzgoja upoštevati tudi glasbeni repertoar mladostnikov, in ta je bil - kot je bilo npr. razvidno iz statistik Službe za študij programa in poslušalcev pri RTV Ljubljana - tudi pri nas v glavnem orientiran $\mathrm{v}$ popularno glasbo.

Po tem kratkem ekskurzu se vrnimo k nemški glasbeni pedagogiki. Jürgen Terhag je v svojem članku o "ne-učljivosti popularne glasbe" iz leta 1984 sicer se reflektiral o vlogi popularne glasbe kot mediju upora proti establishmentu v šoli kot enem osnovnih ideoloških aparatov taistega establishmenta. Toda pedagoška praksa je šla drugo pot. 1980 je bil na Glasbeni akademiji v Hamburgu etabliran modelni projekt, posvečen raziskovanju možnosti študija popularne glasbe na nivoju glasbene akademije. 1984 je sledila konferenca $z$ naslovom "Popmusik und Lernen". In če smo ob koncipiranju te konference temo še opremili z vprašajem, so referati sami - šlo je za predstavitev obstoječih pedagoških projektov na vseh ravneh glasbene vzgoje in izobraževanja pokazali, da ne gre več za to, ČE naj se uči tudi popularna glasba, ampak le - KAKO.

1986 se je konstituiral Arbeitskreis Studium Populärer Musik e.V. kot znanstvena organizacija, ki se ukvarja $\mathrm{z}$ raziskovanjem popularne glasbe na nemško govorečem področju. V tem okvirju se je diskurz o popularni glasbi pričel izvijati iz objema glasbene pedagogike ter se naslonil po eni strani na sistematično muzikologijo, posebno na delo Kurta Blaukopfa, Hans-Petra Reineckeja in kasneje Helmuta Rösinga, po drugi strani pa na glasbeno analizo, kot so jo razvili predvsem na univerzi v Gießnu in ki ima svoje korenine $\mathrm{v}$ izsledkih raziskovanja jazza. $\mathrm{Z}$ novimi generacijami pa so se priceli uveljavljati tudi drugačni pristopi ter prispevki s področja drugih disciplin, od sociologije in umetnostne zgodovine pa vse tja to etnologije, antropologije in literarnih ved. Naj omenim vsaj nekaj tem naših konferenc, referatov oziroma publikacij, ki sem jih v namene boljše preglednosti strukturirala v večja pomenska polja:

1. Teorija: "Popularna glasba v muzikološkem oziroma kulturološkem diskurzu«; "Umetelnost kot umetnost: Fragmenti postmoderne teorije pop in rock glasbe"

2. Analiza: "Beatology: Muzikološki pristop k pesmim Beatlesov“; "Razvoj glasbenih značilnosti pri drum'n'bass“; "Kanonizacija v popularni glasbi«; "Ritmične konstante v popularni glasbi na Balkanu“; "Tradicija poetičnih struktur v blues in rap glasbi"

3. Zgodovina: "Popularna glasba v času Weimarske republike«; "Zgodovina popularne glasbe v Nemški demokratični republiki“; "Kabaret, opereta in revija kot emblemi popularne kulture dvajsetih let"; "O funkciji popularne glasbe $\mathrm{v}$ prvi svetovni vojni“ 
4. Stilni pristop: "Afrojazz in afrobeat"; "Techno“; "Austropop' kot nacionalna pop glasba“; "'Musicalmania' v Nemciji“; "Punk rock in razvoj k ameriškem hard coru"; "Narodno-zabavna glasba med tradicijo, komercializacijo in politiko"

5. Sociološki pristop: "Mladina, mladinska kultura, mladinske scene in glasba"; "Glasba obritoglavcev"; "'Boygroups' in njihovi oboževalci"

6. Glasbeno-etnološki pristop: "Ali je pop ljudska glasba nasega časa"; "Regionalni glasbeni stili in ljudske glasbene tradicije v popularni glasbi $;$; "Recepcija azijske in afriške glasbe v jazzu 60. in 70. let"; "Afriška glasba na nemškem tržišču popularne glasbe «; "Španska tradicija ljudske pesmi v kubanski glasbi«; "Glasba južno-francoskih Manouchov in Gitanov"

7. Glasbeno-psihološki pristop: "Glasbene biografije“; "Aspekti razvoja osebnega glasbenega okusa"; "Rock glasba in vedenje občinstva"; "Funkcija eskapizma v recepciji rock glasbe«; "Psihoanalitična teorija t.i. World music"; "Raziskava razsirjenih oblik zavesti v okvirju techno-party“; "Glasba kot mamilo"

8. Estetski pristop: "Spektakel / Happening / Performance: Rock glasba kot celostna umetnina"; "Problem estetske analize video klipov"

9. Različni aspekti glasbene prakse: "Procesi glasbenega dela v amaterskih skupinah"; "Ekonomska situacija jazz glasbenikov“; "O t.i. 'svobodnjaštvu”; "Rock / Pop / Jazz: Od amaterjev do profesionalcev“; "Popularna glasba kot poklic"

10. Pristop z zornega kota t.i. gender studies: "Glasbenice $v$ damskih orkestrih«; "Ženski zvoki: Prispevki k nenapisani zgodovini glasbe«; "O pomenu, recepciji in delovni situaciji jazz glasbenic"

11. Glasba in tehnologija: "Nove studijske tehnologije"; "Instrumentalna glasba v znamenju elektronike«; "Razvoj kitarskega zvoka v rock glasbi“; "Computerska glasba $v$ industriji nosilcev tona"

12. Glasba in mediji: "Novi glasbeni trendi - novi medialni konteksti“; "Glasbena dramaturgija t.i. servisnih valov"; "De-regulacija medijev in glasbena pestrost“; "O medijski konstrukciji glasbenih svetov“; "Popularna glasba v kontekstu t.i. video culture "; "net.music: Glasba v internetu"; "Medijska tehnologija in glasbena ustvarjalnost"

13. Razno: "Hanns Eisler in jazz«; "Vloga glasbe pri estetizaciji in inscenaciji vojne«; "Vloga telesnosti v rock kulturi"; "Analiza scenskih časopisov"; "Razmišlanja o genezi, obliki in funkciji rock plesa"; "Funkcija popevke v t.i. berlinskem romanu Weimarske republike«; "Vpliv filma na zgodovino rock glasbe «; "K podobi rock glasbenika v filmu"; "Med 'Jesus Christ Superstar' in 'Sympathy for the Devil'. Rock / Pop / Jazz in krščanske religije“

S tem lapidarnim pregledom našega dela se polagoma pricenjam priblizevati odgovorom na vprašanja, ki so bila zastavljena v razpisu za današnjo konferenco. Med ključne probleme sodi brez dvoma definicija predmeta raziskave. Na ustanovni konferenci International Association for the Study of Popular Music je Philip Tagg, eden od prvoborcev na tem področju dejal, da se raziskovanje popularne glasbe ukvarja $\mathrm{z}$ vsem tem, kar ne pokrivata ne $\mathrm{v}$ raziskovanje zgodovine klasične glasbe orientirana muzikologija ne glasbena etnologija in kar se pravzaprav nanaša na dobrih $90 \%$ vse 
glasbe. Ta definicija per exclusionem je zvenela svoje čase zelo radikalno, čeprav se je za njo se vedno skrival primat glasbenega objekta, to je glasbenega dela, pesmi ali komada po vzoru klasične muzikologije.

Da pa tovrstno izhodišče ne more biti edina iztočnica, kaže vrsta konkretnih primerov. Vzemimo npr. Novoletni koncert z Dunajskimi filharmoniki. Kar se tiče repertoarja, sodijo valčki in polke izpod peresa članov dinastije Strauß nedvomno k "popularni glasbi“. Toda: ali je $\mathrm{v}$ danem primeru ta klasifikacija ustrezna? Namesto plesnega imamo vrhunski simfonični orkester z znanimi dirigenti. Dogodek se odvija v dvorani "Musikvereina", tradicionalnem templju klasične glasbe. Občinstvo se rekrutira iz obiskovalcev simfoničnih koncertov in si - razen če ni izrecno povabljeno $\mathrm{k}$ ploskanju - na vse kriplje prizadeva mirno sedeti na svojih sedežih. In namesto da bi se prisotni vrteli v ritmu valčka, opravijo to solisti baleta Dunajske državne opere. Lahko ob tej rekontektualiziji še govorimo o "popularni glasbiu? Ali pa so sedaj Straußovi valčki postali "resna glasbau?

Poglejmo si se nekatere druge primere. Islandska pevka Björk je v svojih intervjujih večkrat povdarila, da je zanjo eden od najvažnejših vzornikov Karl-Heinz Stockhausen. $\mathrm{V}$ njeni glasbi sicer ne najdemo nobenih neposrednih povezav. Pač pa $\mathrm{V}$ umetniškem pristopu, $\mathrm{v}$ nenehnem iskanju novega, v njenem odnosu do lastnega dela. Ali je Björk na osnovi teh kriterijev predstavnica klasične avantgarde ali pa ostaja pop zvezda? In kam bi s tremi tenorji, ki jih sicer prodajajo pod nalepko "klasika", ki pa pojejo pravzaprav vse, kar se da dobro peti? Ali pa z Vanesso Mae in Niglom Kennedyjem? Kam naj vtaknemo "Heroes Symphonie“ Philippa Glassa, Kronos kvartet, ki interpretira "Purple Haze" Jimmyja Hendrixa, skladbo "Yellow Shark" Franka Zappe in ne nazadnje Paula McCartneya, ki je napisal tudi vrsto bolj ali manj uspešnih klasičnih del?

Oziroma, vprašajmo se drugače: Ali so tovrstna vprašanja sploh smiselna? Glasbeno življenje - in to je zame osnovni predmet muzikološkega raziskovanja - je živ organizem, ki se nenehno in tudi vedno hitreje spreminja. Obsega glasbenike in glasbena dela, izvajalce in poslušalce, medije in nosilce tona, glasbene organizatorje in glasbeno novinarstvo, glasbeno industrijo in sorodne ekonomske dejavnosti ter zapletene, mnogoznačne in včasih tudi paradoksne odnose med njimi. Samo na osnovi glasbene strukture, pa naj je se tako pomembna, zatorej ne moremo definirati ne predmeta raziskovanja popularne glasbe kakor tudi ne muzikologije v celoti. In tudi če tematski pregled nasega dela na prvi pogled zavaja h predstavi, da je treba klasični muzikološki raster le "napolniti" $s$ temami z "druge strani" demarkacijske meje med "resnim" in "popularnim", leži po mojem mnenju bistvo raziskovanja popularne glasbe nekje drugje. Tukaj gre predvsem za zorni kot, s katerega se glasbenim fenomenom približujemo oziroma za način, kako jih obravnavamo. Konkretno gre za celostni pristop k materiji, ki upošteva mnogo več kot le odnos med delom in njegovim ustvarjalcem in ki skuša ujeti v smiselne aksiome predvsem kompleksnost in polivalentnost glasbenih procesov.

Glasbeno življenje s svojo neskončno pestrostjo nam zatorej nudi vrsto različnih oblik obravnave in se mu lahko približamo iz najrazličnejsih zornih kotov. S tem se seveda odpira vprašanje metodologije, odnosa do drugih disciplin in verifikacije 
znanstvenih dosežkov. Samo s klasičnimi muzikološkimi pristopi, kot so npr. biografika, glasbena analiza ali hermenevtika, kompleksnih glasbenih fenomenov ne moremo raziskati. Zato se zavzemam za pluralizem metodoloških pristopov ter interdisciplinarnost raziskovanja, iskanje dialoga $\mathrm{z}$ drugimi znanstvenimi panogami, vodenje konstruktivnega diskurza med različnimi pogledi, šolami in teoretskimi pozicijami ter za ustvarjanje ustreznih organizacijskih infrastruktur, forumov in platform, na katerih lahko predstavniki različnih znanstvenih vej diskutirajo aktualne teme in fenomene. Pri tem se nam odpira širok spekter potencialnih kooperacijskih partnerjev od etnologov in sociologov preko politologov, ekonomistov, antropologov in semiotikov pa tja do raziskovalcev s področja medijev in komunikacijske teorije oziroma anglo-ameriških gender in cultural studies.

In tam, kjer velja paradigma različnih pristopov, se relativira tudi domnevna premisa o t.i. objektivnosti muzikološkega raziskovanja. Gotovo obstaja neka določena intersubjektivnost opazovanih procesov. Toda hkrati se moramo zavedati, kot je to poudaril že Hans-Peter Reinecke v svojem članku o "Popularni glasbi in prestrašenih muzikologih", da je predmet raziskovanja vedno neposredno povezan s svojim opazovalcem, ki vanj projicira svoj lastni svet ter svoje lastne probleme in zategadelj posebno teme, ki se nanašajo na proučevanje lastne družbe in kulture vsebujejo poleg objektivnih izjav tudi določene subjektivne odzive. Prav tako ne smemo sprégledati dejstva, da se s številom dimenzij predmeta proučevanja poveča tudi število asocijacijskih povezav in interpretacijskih alternativ. Rezultati nasega raziskovanja so zatorej - podobno kot pri glasbi sami - lahko le interpretacijske ponudbe, ki jih dajemo "potrošnikom" našega dela, t.j. kolegom, glasbenim ustanovam, medijem, "izobraženim bralcem" ali glasbenim pedagogom, na voljo v nadaljnjo reinterpretacijo in rekonstrukcijo. To pa je meja, ki je - kljub želji, najti edino zveličavno resnico - tudi dosedanja razmišljanja o glasbi in kulturi niso uspela prekoračiti.

\section{Viri in literatura:}

Barber-Kersovan, Alenka \& Poppensieker, Karin (1990): Rock/Jazz-Info 1990. Aus-, Fort- und Weiterbildungsangebote in der BRD. Hamburg.

Baacke, Dieter (1972): Beat, die sprachlose Opposition. München.

Blaukopf, Kurt (izd.) (1974): Neue musikalische Verhaltensweisen der Jugend. Mainz. Blaukopf, Kurt (1982): Musik im Wandel der Gesellschaft. München, Zürich.

Brake, Mike (1981): Soziologie der jugendlichen Subkulturen. Eine Einführung. Frankfurt/M., New York.

Bruhn, Herbert \& Rösing, Helmut (izd.) (1998): Musikwissenschaft. Ein Grundkurs. Rowohlts Enzyklopädie. Reinbek bei Hamburg.

Clarke, John et al. (1979): Jugendkultur als Widerstand. Milieus, Rituale, Provokationen. Frankfurt/M.

Frith, Simon (1983): Sound Effects. Youth, Leasure and the Politics of Rock'n'Roll. London.

Frith, Simon (izd.) (1989): World Music, Politics and Social Change. Manchester.

Frith, Simon \& Goodwin, Andrew (izd.) (1990): On Record. Rock, Pop and Written Word. New York. 
Hall, Stuart \& Jefferson, Tony (izd.) (1975; 1996): Resistance Through Rituals. Youth Subcultures in Post-War Britain. London.

Hebdige, Dick (1979; 1983): Subculture. Die Bedeutung von Stil. In: Diedrichsen, D. \& Hebdige, D. \& Marx, O. D.: Schocker. Stile und Moden der Subkultur. Reinbek bei Hamburg.

Hemming, Jan \& Markuse, Brigitte \& Marx, Wolfgang (2000): Das Studium der Musikwissenschaft in Deutschland. Eine statistische Analyse von Lehrangebot und Fachstruktur. V: Die Musikforschung, st. 53.

Kopiez, Reinhard et al. (izd.) (1998): Musikwissenschaft zwischen Kunst, Ästhetik und Experiment. Festschrift Helga de la Motte-Haber zum 60. Geburtstag. Würzburg.

McClary, Susan (1990): Start making sense! Musicology wrestles with Rock. V: Frith, S. \& Goodwin, A. (izd.): On Record. Rock, Pop and Written Word. New York.

Rauhe, Hermann (1975): Jugend in der heutigen Gesellschaft. Analysen und Perspektiven. Hamburg.

Reinecke, Hans-Peter (1980): Musikalische Unterhaltung, eine Lebensform. Neue Zeitschrift für Musik, st. 1.

Reinecke, Hans-Peter (1992): Popularmusik und geängstigte Musikologen. V: Hoffmann, B. \& Pape, W. \& Rösing, H. (izd.): Rock / Pop / Jazz im musikwissenschaftlichen Diskurs. Ausgewählte Beiträge zur Popularmusikforschung. Hamburg.

Riesman, David (1950; 1958): Die einsame Masse. Reinbek bei Hamburg.

Rösing, Helmut (1996): Was ist "Populäre Musik"? - Überlegungen in eigener Sache. V: Beiträge zur Popularmusikforschung, st. 17.

Rösing, Helmut (izd.) (1986 - 1999): Beiträge zur Popularmusikforschung. Bd. 1 - 27: Kassel und Karben.

Rösing, Helmut \& Schneider, Albrecht \& Pfleiderer, Martin (izd.) (2002): Musikwissenschaft und populäre Musik. Versuch einer Bestandsaufnahme. Frankfurt/M., New York.

Rösing, Helmut \& Barber-Kersovan Alenka \& Fuchs, Armin (izd.) (1985): Popmusik und Lernen. Jazzforschung, st. 17.

Roszak, Theodor (1971): Gegenkultur. Wien.

Sim, Stuart (izd.) (1998): The Icon Critical Dictionary of Postmodern Thought. Cambridge.

Tagg, Philip (1979): Kojak. 50 Seconds of Television Music. Towards the Analysis of Affect in Popular Music. Göteborg.

Terhag, Jürgen (1984): "Die Un-Unterrichtbarkeit aktueller Pop- und Rockmusik. Gedankengänge zwischen allen Stühlen. V: Musik und Bildung, st. 5.

Terhag, Jürgen (1989): Populäre Musik und Jugendkulturen - Über die Möglichkeiten und Grenzen der Musikpädagogik. Regensburg.

Wicke, Peter (1997): Popmusikforschung in der DDR. V: Maas, G. \& Reszel, H. (izd.): Popularmusik und Musikpädagogik in der DDR. Augsburg. 